\title{
EL RETRATO DE CARLOS I DE VAN DYCK DEL PALACIO DE SUMMERSET IDENTIFICADO EN LOS FONDOS DEL MUSEO DEL PRADO
}

\author{
POR \\ MATÍAS DíAZ PADRÓN \\ Conservador del Museo del Prado
}

El retrato ecuestre de Carlos I de Inglaterra del museo del Prado, fue tenido siempre por copia de Van Dyck y en los depósitos desde el legado de Fernando VII. Hoy es posible probar su autenticidad y restitución a Van Dyck de dimensiones, calidad y técnica idéntica al conocido en la National Gallery. Al estudio estilístico unimos el hallazgo documental en lista de obras que proponen a Cárdenas para la colección del rey de España el 25 de mayo de 1654. La otra réplica la adquirió B. Gerbier el 21 de junio de 1650, cuatro años antes de la memoria de la almoneda del rey inglés citada. De aquí que son dos originales, no uno. El del museo del Prado que hoy restituimos a van Dyck cubre el espacio de la documentación hasta ahora conocida en la colección de Felipe V en la Granja en 1727, con localización en 1680 en las colecciones del marques de Mejorada, y Ensenada a continuación.

Sigue un análisis de las fuentes de inspiración copias localizadas y su historia externa en los inventarios y testamentarías en España. Esta réplica (como copia hasta ahora en el museo del Prado) constaba en la memoria de 1654 así: "Este cuadro es lo mejor que hizo Van Dyck". Un alto precio y localización en el palacio de Summerset.

Palabras clave: Van Dyck. Carlos I de Inglaterra. Retrato ecuestre. Siglo XVII. Museo del Prado.

The Equestrian Portrait of Charles I of England, coming from the Spanish royal collections and in the Prado Museum since the $19^{\text {th }}$ century, has always been considered to be a copy of Van Dyck. It is now possible to demonstrate the authenticity of this work, the dimensions, quality and technique of which are identical to the Van Dyck in the National Gallery. The author studies the Madrid autograph replica stylistically and through the use of documentary materials ranging in date from 1650 to 1727 . In 1654, when it was in Summerset Palace, the Prado version was considered to be "the best by Van Dyck," and through this study the work is returned to his hand.

Key words: Van Dyck. Charles I of England. Equestrian portrait. $17^{\text {th }}$ century. Prado Museum. 
Desde el traslado de las Colecciones Reales al Museo del Prado por decreto de Fernando VII, el lienzo de Carlos I de Inglaterra a caballo [Fig.1] [ $\mathrm{n}^{\circ}$ 1.501] que hoy restituimos a Van Dyck ha estado oculto al público en los depósitos del museo, siempre catalogado y desestimado como copia de taller o escuela del famoso discípulo de Rubens y sin especial atención ${ }^{1}$. El estado de conservación de la capa protectora ha sido un obstáculo para su correcta valoración ${ }^{2}$. No obstante, y pese a esta limitación, es posible reconocer la calidad equiparable del lienzo del Prado al mejor conocido y estudiado de la National Gallery de Londres [Fig.2] $]^{3}$. Con ocasión a los estudios de la obra de Van Dyck en España ha sido posible la revisión más detenida de esta primera o segunda réplica del monarca inglés, y puesta a revisión crítica la documentación de este interesante retrato necesaria para desgranar la compleja trama de su historia externa. El reconocimiento de su alta calidad lo apunté ya en los últimos catálogos razonados del museo ${ }^{4}$ y decidida en reciente conferencia a tenor de la Exposición y recreación del Buen Retiro: "Felipe IV y Van Dyck". 5.

Junto al estudio analítico y estilístico con resultado positivo, viene a legitimar la autoría del retrato de Carlos I del Museo del Prado (como primera o segunda réplica del de la National Gallery) la relación de pinturas de la fabulosa colección del monarca inglés después de su condena y muerte, que puso en venta el parlamento inglés.

Dos personalidades del momento en indiscreta enemistad, Carlos I y el embajador español don Alonso de Cárdenas, son importantes para la historia de España, y para este retrato en particular. De Carlos I poco se ha escrito salvo su viaje a Madrid siendo príncipe de Gales con idea de fijar una alianza matrimonial, que pudo cambiar los destinos de los dos países ${ }^{6}$. La impresión que le

${ }^{1}$ L. 366 x $281 \mathrm{~cm}$. Lleva inscrito en el lado inferior izquierdo el no 549, y en el, lado inferior derecho $\mathrm{n}^{\circ}$ 2.671.Catálogos de 1878-1907 ( $\mathrm{n}^{\circ}$ 1344b), 1910-1920 ( $\mathrm{n}^{\circ}$ 1344c) 1920-1996 n 1501; P. Beroqui, "Adiciones y correcciones al Catálogo del Museo del Prado" Boletín de la Sociedad Española de Excursiones, 1917, p.222; O. Millar, Pictures in the Royal Collection, Tudor, Stuart and Early Georgian Pictures, 1963, p.41; Gregory Martín, The Flemish School circa 1600-circa 1900, 1970; M. Díaz Padrón, La Pintura Flamenca en el Museo del Prado. Catálogo razonado, 1975, p. 125126, lám 84; E. Larsen The Paintings of Anthony van Dyck, 1988, t. II, p. 477, nº A199; Hernando Fernández Miranda Inventarios Reales. Carlos III, 1789-1790, 1988, vol. II, p. 256; J. L. Gonzalez García \& M. Riaza de los Mozos, "Del saber de la Academia al gusto del amateur: las colecciones de pintura y escultura clásica de Felipe V", Arte en la Corte de Felipe V. cat. Exp., Madrid 2002-2003, p.192; Á. Aterido, J. Martínez Cuesta, J. J. Pérez Preciado, Colecciones de pinturas de Felipe Ve Isabel de Farnesio, I-II, Madrid, 2004, T. II, p.393, n 371; S. J. Barnes, N. De Poorter, O. Millar, H. Vey, Van Dyck. A Complete Catalogue of the Paintings, Yale, New Haven- Londres, 2004, p. 470; J. Brotton, The sale of the Late King's Goods, Londres 2006, p. 248.

2 El lienzo del Prado presenta gran suciedad acumulada que desmejora su apreciación. La junta de dos paños acusa la unión, también en la parte superior otra de unos treinta centímetros evidencia el mismo hecho. Pequeños repintes aislados en el lienzo, uno pequeño sobre el rostro, y en el caballo con más descuido del límite de la laguna.

${ }^{3}$ L. 367 x 292. Londres, National Gallery ( $n^{\circ} 1172$ ). El retrato del monarca inglés lleva inscrito en la cartela del árbol: "CAROLVS / REX MAGNAE / BRITAÑIAE" [Estudiado en profundidad por G. Martin,op.cit. 1970, p.41, n 1172; véase también Millar, op.cit. 1972, p. 316; Larsen, op.cit. 1988, nº 795; Barnes et all op.cit. 2004, p. 468, nº IV. 51].

${ }^{4}$ M. Díaz Padrón, El Siglo de Rubens en el Museo del Prado, 1995, T. I, pp. 502-503.

5 Díaz Padrón, "Felipe IV y Van Dyck", Conferencia en el ciclo El Palacio del Rey Planeta. Felipe IV y el Buen Retiro. Museo del Prado, Madrid, 22-X-2005.

${ }^{6}$ Nos parece obligado recordar la personalidad de este monarca inglés que se cruza entre líneas en la historia de España recordando sólo aquella romántica visita a la infanta María, hermana de Felipe IV, (M. Hume, Le Cour df Philippe IV et la décadence de l'decadence de L'Espagne (1621-1663), p. 82, 1912; G. Huxley, Endimión Porter: the life of a Courtier, Londres 1959, p. 84). Aquel proyectó fracasó como es sabido pero el contacto del príncipe con el monarca español fomentó sus aficiones artísticas y tanto el ejemplo de El Escorial como el gusto por la escultura clásica y la etiqueta española influyó en sus ideales estéticos. La imagen del rey inglés la fijó Velázquez en aquel viaje de 1623, (Pacheco, Arte de la Pintura, 1946, tomo I, p.156 "hizo tambien de camino un bosquexo del príncipe de Gales que le dio cien escudos"; G. Huxley, Endimión Porter, 1959, pp. 111-112) pasarían años de distanciamiento y aproximación por razones de Estado que explica la venida de Rubens a Madrid en 1628 y momentos tristes que siguen con el cambio de régimen republicano de Cromwell que facilita la compra de esta y otras pinturas de la colección real del monarca decapitado. Existieron unos años antes momentos de 
produjo la sociedad española tuvo consecuencias positivas en su pasión por las artes y el espíritu de emulación que lleva consigo el retrato como signo de poderío. Del lado de Cárdenas hay motivos para verle como el gestor inteligente que logra la adquisición del retrato. No hay duda que actuó con conocimiento análogo al Cardenal Infante pocos años antes de adquirir para España los Van Dycks de juventud que poseía Rubens en su colección. Cárdenas hizo lo mismo en la colección de Carlos I con las pinturas más bellas de su etapa madura de Van Dyck en Inglaterra y Amberes ${ }^{7}$.

En la memoria de las pinturas de la almoneda de Carlos I del 25 de mayo de 1654, consta un retrato ecuestre original de mano de van Dyck que figura como: "(Fol. $2 r)$ Otro quadro de más de çinco varas de alto y quatro/ de ancho, poco más a menos, con el retrato del/ rey Carlos a cavallo, de mano de Uandyck. Tasado en 1200 (ducados)" 8 . La misma memoria añade al margen la siguiente anotación: "este cuadro es lo mejor que hizo Van Dyck"9, y precisa su localización "en los palaçios de Summerset y Antoncourt" ${ }^{10}$.Es conocido que la réplica de la National Gallery procede del Palacio de Hampton Court ${ }^{11}$, por lo que es de suponer que el que nos ocupa proceda

intercambio de retratos de la familia de uno y otro monarca, pero de estos retratos no tenemos buena imagen pues del lado inglés se enviaron copias de taller con el visto bueno de Van Dyck, que no engañó a los españoles (Sainsbury, Original Unpublished Papers illustrative of the life of Sir Meter Paul Rubens 1859, p.193; Trapier, "Sir Arthur Hopton and the interchange of paintings between Spain an d England in the 17th century", Part 11, Connoisseur, clxv 1967, $\mathrm{n}^{\circ}$ 165, p.62) desde el lado español se paga con igual moneda en la ingenua pretensión de hacer creer que el pintor era Velázquez, (E. Harris, "Velázquez and Charles I" Journal of the warburg and courtauld institute, 1967t. 30, p.417) El caso es que ni uno ni otro lote responden a las expectativas de obras de primera mano de los mas grandes retratistas de Europa con un compromiso incumplido en estas circunstancias resumimos la realidad de un retrato del príncipe de Gales que hizo Velázquez en su juventud y otro que nos llega a España en trastes circunstancias pero afortunadas para el coleccionismo español de un original del rey inglés en contrapartida al de Velázquez oculto en los fondos del museo del Prado. Del coleccionismo del rey inglés son fundamentales los estudios de Millar “The inventories and Valuations of the King's goods, 1649-1651” Walpole Soc., xxxxiii (1972); Idem, The age of Charles I, 1972; Idem, The King's Arcadia: Iñigo Jones and the Stuart Court,1973,Idem, The Queen's Pictures, 1977; H. M. Colvin, D. R. Ransome, J. Summerson History of the King's Works, 1982.

7 Cárdenas está en Londres y su gestión fue definitiva en la selección del retrato del monarca inglés que estudiamos cuyo listado de obras le permitió seleccionar pinturas para el rey y sus colegas españoles. Su buena relación con los independentistas republicanos facilitó su permanencia en Londres y la adquisición de las pinturas del rey inglés en disputa con los muchos coleccionistas de Europa, incluso de testas coronadas, que las ambicionaban. Mucho ayudó en ello don Luís de Haro, consiguiendo neutralizar las intenciones del rey francés. Estuvo como agente en Londres en 1631, embajador de 1640-1655, espacio que comparte con la política republicana de Cromwell desde 1650. Trabajó en la mayoría de los casos sin intermediarios contando con el apoyo de don Luís de Haro que de hecho ocultaba la intervención del rey. Aunque el punto de mira estaba más inclinado a la pintura italiana (María Jesús Muñoz Gonzalez "Las compras de pintura italiana realizadas en la almoneda de Carlos I de Inglaterra por Alonso de Cárdenas" en El Mediterráneo y el arte español. Actas del XI Congreso de CEHA, septiembre de 1996, Valencia 1998, p.198- 200) las pinturas flamencas tuvieron un interés indiscutible aunque sin estudiar como las concernientes a Italia. (Madrid, 2002, Cat. Exp. Museo del Prado La Almoneda del siglo, C. Brown, J. Eliot, p. 279-286).

8 [Caja 182-195 memoria de las pinturas y tapicerías de la almoneda del rey Carlos I de Inglaterra. 25 de mayo de 1651. (fol. 1r) memoria de las pinturas originales del Rey, más notables y de mayor/ estimación, que se uenden en los palaçios de Summerset y Antoncourt, y/ de los preçios dellas”. En La almoneda del siglo, Cat. Exp.cit. Madrid, 2002, p.285 (apéndice documental).

9 Brotton \& Mc Grath, "The Spanish acquisition of King Charles I's paintings: the letters of Alonso de Cárdenas, 1649-51", Journal of the History of Collections (en prensa, anunciado por Brotton 2006, p. 386, nota 27).

10 “II. MEMORIA DE PINTURAS Y TAPICES EN VENTA 1. Caja 182-178 (Fol. 1r) Memoria de las primeras, mejores y más ricas tapicerías del rey de Inglaterra, / que por orden del Parlamento, se tratan de vender en la ciudad de Londres;/ sacada de la original que embió el $S^{r} D^{n}$ Alonso de Cárdenas. 2. caja 182-195 Memoria de las pinturas y tapicerías de la almoneda del rey Carlos I de Inglaterra. 25 de mayo de 1654. Incluye cuenta de 8 de agosto de 1651. (Fol. 1r) Memoria de las pinturas del Rey, más notables y de mayor/ estimación, que se uenden en los palaçios de Summerset y Antoncourt, y/ de los preçios dellas". [Vid Madrid, 2002, Cat. Exp., La almoneda del siglo, p. 284 y 285 (apéndice documental)].

11 Así lo confirma el inventario de las pinturas del rey inglés redactado por Van der Doort (1637-1640): "at present in the Prince's Gallery at Hampton Court" [Millar, "Abraham van der Doort's Catalogue of the Collection of Charles I", Wallpole Society, 1960, XXXVII, p. 62, en n 2] 
del palacio de Summerset. En cualquier caso, el precio está muy por encima de las pinturas tasadas en la misma memoria, sólo superado por dos o tres excepcionales de Tiziano, lo que prueba la estima entonces por este cuadro que hoy tiene el Museo del Prado, más si tenemos en cuenta que el género del retrato está valorado por debajo de la composición histórica y mitología. La alta tasación, la descripción y las medidas podían dar motivos para pensar en el conocido de la National Gallery de Londres; pero éste había sido adquirido por Baltasar Gerbier cuatro años antes, el 21 de junio de $1650^{12}$. Esto no ha llamado la atención de la crítica hasta ahora, tampoco el hecho que existían dos retratos idénticos de mano de Van Dyck en las colecciones de Carlos I, práctica frecuente en la producción de Van Dyck y la naturaleza de este tipo de retrato oficial para los palacios de la corona.

Es sabido que don Alonso de Cárdenas compraba obras para el marques del Carpio don Luis de Haro y Guzmán y para el rey que permanecía en la sombra ${ }^{13}$.

O. Millar llamó la atención de un ejemplar comprado por Cárdenas que fue visto en El Escorial ${ }^{14}$. Esto tiene algún sentido al conocer que el marqués del Carpio don Luis de Haro, fue el responsable más directo de las colecciones del monasterio con la idea de concebirlo como un museo público ${ }^{15}$. Es sabido que muchas de las pinturas religiosas de la colección de Carlos I tuvieron por destino expreso El Escorial para cuya decoración trabajaron Velázquez, Gómez de Mora y el Padre Santos ${ }^{16}$. No sería especular en demasía pensar en los reparos del rey español a tener cerca este retrato de un amigo de juventud, cuyas colecciones fueron adquiridas en circunstancias tan tristes como oportunistas.

El lienzo del Museo del Prado es idéntico al de la National Gallery de Londres, estudiado con detenimiento por Gregory Martin, cuyos juicios y criterios son válidos para la réplica que nos ocu$\mathrm{pa}^{17}$. Uno y otro son muy próximos en medidas, sentido del espacio, contenido iconográfico y calidad estética, repitiendo el texto de la cartela que cuelga del árbol a la derecha, con caracteres latinos alusivos al retratado y su condición real: "CAROLUS I / REX MAGNAE / BRITANIAE"18.

De perfil y a caballo, el rey marcha al paso de derecha a izquierda, bajo un fondo de boscaje frondoso. Lleva bastón de mando, armadura completa con guanteletes y collar de la Orden de la

\footnotetext{
12 Valorado en 200 libras, vendido a Sir Baltasar Gerbier el 21 de Junio de 1650 (S.P. 29/447, 24, I; Millar 1963, p. 95, en $\mathrm{n}^{\circ}$ 144]. Posteriormente vendido en Amberes a Maximiliano II en 1698; en 1706 pasa a Inglaterra [Millar, op.cit., 1963, p.95]: Para la historia externa de la versión de la National Gallery, ver Millar, op.cit., 1963, I, p.95, nº 144; Martín, op.cit., 1970, p. 44; Larsen, op.cit., 1988, p.314; Brotton 2006, p. 243 (dice que se trata de un retrato sin identificar]. Gerbier debió estar al tanto de las ventas también adquirió el retrato de Carlos V con perro de Tiziano, que Felipe IV había regalado al príncipe de Gales en 1623, y se lo vendió a Cárdenas al momento en 50 libras más de lo adquirido por él (200 libras) volvió por tanto a Madrid después de treinta y siete años (Millar, 1970-72 p.269)

13 Vid. Cat. Exp. cit, Madrid 2002, p.81

14 "Afterwards in Oliver's Days, the then Spanish Ambassador here Don Alonso de Cardenes bought... $y^{e}$ King on the Dun Horse by Van-Dyck... which same say remain in the Escuriall to this Day, tho; others, affirm the Picture of the King Charles on the Dun Horse is now in the posesion of the Duke of Bavaria, who bought it off one myn-Heer Van Cullen" (en tiempos de Oliver [Cromwell] el décimo embajador español aquí don alonso de Cárdenas compró ... el rey sobre el caballo pardo de Van Dyck.. que algunos dicen recordar en El Escorial en estos días; otros afirman que la pintura del rey Carlos sobre el caballo pardo está ahora en posesión del duque de Bavaria quien lo compró a van Cullen) [Vertue Note Books, The Walpole Society, XX, 1931-1932, p.147; Vid Martin, op.cit 1970, p.46, nota 48].

15 P. Beroqui, "El Museo del Prado. Notas para su Historia", Boletín de la Socieda Española de Excursiones, 1930, p.628, nota 1; M. Díaz Padrón, La pintura Flamenca del siglo XVII en España, tesis doctoral, Universidad Complutense, Ms.,Madrid, 1976, t. I , fol. 170 y 210;

16 Palomino, El Museo Pictórico y Escala Óptica, 1715, ed.1947, p.922.

17 Martin, op.cit., 1970, p. 41, n ${ }^{\circ} 1.172$.

18 La replica de la National Gallery llevaba una exacta inscripción, pero se consideró una probable introducción posterior de la sigla romana I y fue levantado por estimarlo posterior a la inscripción misma. G. Martín, op.cit, Londres, 1970, p. 41 y 44 , nota 4.
} 
Jarretera y la medalla de San Jorge y el dragón ${ }^{19}$. Le sigue un escudero llevando el yelmo, que se ha tenido por Sir Thomas Morton ${ }^{20}$. La plasticidad del caballo castaño oscuro con largas crines domina el monte bajo con frondosa espesura. El verdor de la tierra del primer y último plano, y la luz rojiza de la tarde es propio en las tierras húmedas del norte. La frondosidad de las ramas funden el paisaje y el retrato. Van Dyck captó el alma de la naturaleza en ósmosis perfecta con la imagen del monarca. Su toma de contacto con la naturaleza está en su capacidad interpretativa del paisaje que motivó la publicación individual de apuntes y aguadas de esta temática ${ }^{21}$. El Estudio de árbol que conserva el British Museum [Fig. 3] ${ }^{22}$ es el modelo de árbol en el horizonte que sirvió a los retratos ecuestres de la National Gallery y Museo del Prado. El caballo que monta el rey inglés es un ejemplar de raza española ${ }^{23}$, casta que se tenía por la más apropiada "para montar los reyes en las grandes ceremonias" 24 .

La fórmula del retrato ecuestre del monarca inglés está estrechamente ligada a la tradición heroica de la Antigüedad, que tuvo por fuente lejana el Retrato ecuestre de Marco Aurelio, con repercusión en el Gattamelata de Donatello y el Colleone de Verrocchio. Millar vio la inspiración más inmediata en un grabado de Thomas Cockson del II conde de Essex a caballo $^{25}$ que debió inspirarse en la escultura de Marco Aurelio, y pudo conocer a través de grabados y estampas de la época. Estos grabados no tienen la precisión monumental y armónica del Caballero, la Muerte y el Diablo de Durero (1513) muy divulgado en toda Europa [Fig. 4] ${ }^{26}$ y deudor a su vez del imponente cabello y caballero de Verrocchio -expresión del poderío y confianza del hombre del Renacimiento- que el maestro alemán vio en su visita a Venecia hacia 1505-150627. Aquí está la fuente directa de Van Dyck. Su fascinación por Durero es un hecho probado en otras ocasiones. Había utilizado sus grabados en obras de juventud, interpretando libremente el rostro del Caballero de la muerte 28 . La inclusión del escudero, como el bosque que contribuye

19 “Order of the Garter": Orden militar creada por Eduardo III hacia 1348, reservada al monarca, al príncipe de Gales y a los más altos méritos guerreros y militares. Su símbolo es una liga azul oscuro, de borde dorado en las que aparecen en francés las palabras "honi soit qui mal y pense", la insignia de la orden incluye un collar y una insignia colgada realizada en oro y esmalte con san Jorge a caballo (conocida como el George) y una segunda medalla (conocida como George menor) con una imagen similar se lleva en el fajín. [Ashmole, The Institution, Laws \& Ceremonias of the noble order of the Garder, 1672, pp. 226-8].

20 Identificación mantenida tradicionalmente que no está comprobada [Véase Walpole, Anectodes of Paintings in Englandwith some account of the principal artists, ed. Dallaway, II, 1826, p. 214; Smith, Anthony Van Dyck. Catalogue Raisoné, III, Londres, 1931, seguido de Passevant, Kunstreise durch England und Belgien, 1831, p. 177; Vid. Martin, op.cit., 1970, p. 43, nota 35]

${ }^{21}$ Royalton-Kisch, The Light of Natur: Landscape Drawings and Watercolours by Van Dyck and his Contemporaries, Rubenshuis, Amberes- British Museum, Londres, 1999, p.103, fig.20a. Una copia del dibujo se atribuye a Tomas Girting en colección privada.

22 Pluma y tinta marrón, aguada y acuarela, 195 x 236 mm. Londres, British Museum (00.9-50). [Vey, Die Zeichnungen Anton Van Dycks, Monographen des " National Centrum voor de Plastische Kunsten Van XVI de en XVII de Eeuw, 1962, no 303 ; Royalton-Kish, La Lumière Naturelle. Dessins et aquarelles de paysage de Van Dyck et ses contemporains, Cat. Exp. Amberes 1999, p.103, n²0].

23 L. Apsley, Bridleways Through History, 1948, p. 295.

24 W. Cavendish, Duke of Newcastle, A general system of horse manship, Amberes, 1658, Londres, 1743 [Cit. Justi, Velázquez y su Siglo, ed. 1953, p. 426]

25 Véase el grabado en Millar, op.cit. 1963, I, p. 95, fig. 4.

26 Véase Moffitt, "Le Roi à la ciasse? : Kings, Christian Knights and Van Dyck’s Singular "Dismounted equestrianportrait of Charles I", Atributs et Historiae, 7, 1983, p. 82.

27 Liedtke, The Royal Horse and Rider, Painting, Scullpture, and Horsemanship 1500-1800, Nueva York, 1989, p. 180

28 Dibujo 201 x 266 mm. Museo de Berlin, gabinete de estampas. Vey, Op.cit. 1962, no 29; Díaz Padrón , op.cit., 1995, t I, p.426 y 432. Dibujo Albertina de Londres Vey, op.cit 1962, nº 72. 


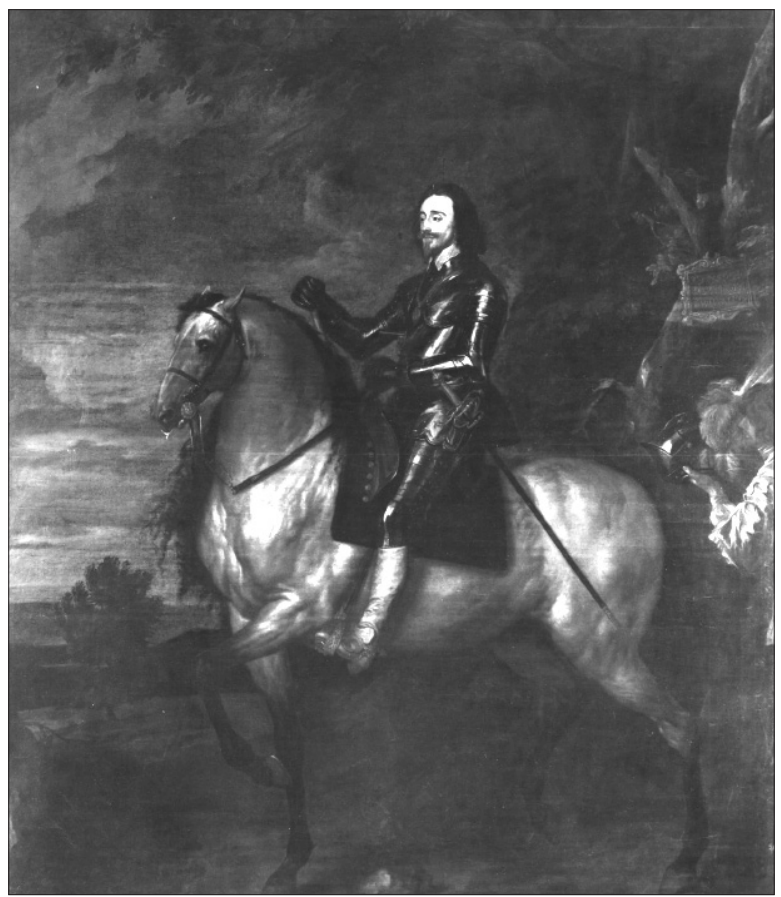

Fig. 1. Antón Van Dyck, Carlos I a caballo, Madrid, Museo del Prado.

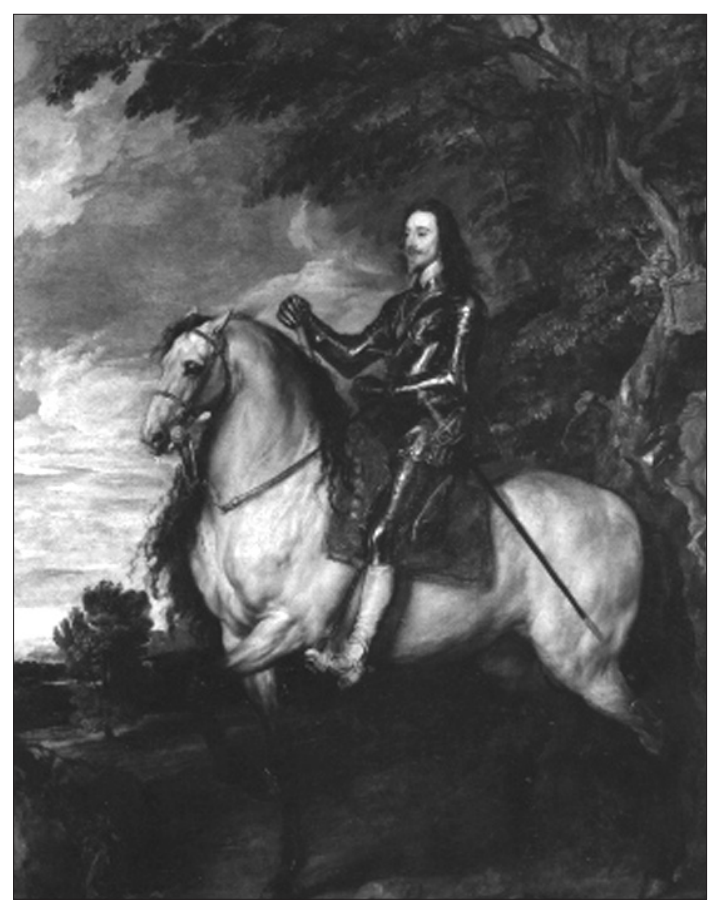

Fig. 2. A. van Dyck. Retrato de Carlos I a caballo. Londres, National Gallery.

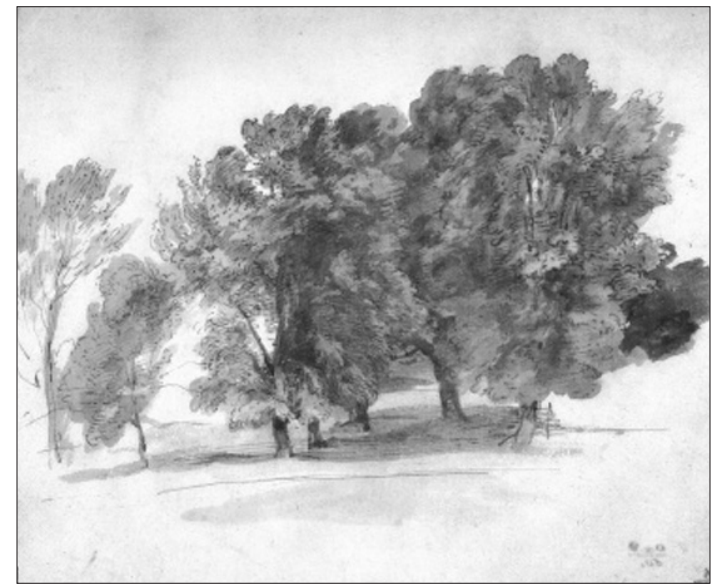

Fig. 3. A. van Dyck. Estudio de árboles. Londres, British Museum. 
a la prestancia del retratado también deriva del grabado de Durero, que se divulgó más que los de Marco Aurelio ${ }^{29}$, Galva de J. Stradanus ${ }^{30}$ y Domiciano de A. Tempesta ${ }^{31}$, de similar diseño y función.

El hecho es que los reyes del siglo XVII revivieron los sueños de los emperadores romanos en estos grabados32: una evocación que tuvo su mejor icono en el retrato de Carlos V en la batalla de Mühlberg de Tiziano, (Museo del Prado). Bellori reconoció en este retrato el prototipo que inspiró a Van Dyck para los de Carlos I de Inglaterra ${ }^{33}$. Pero el corcel que monta Carlos V va al galope de perfil al espectador, mientras que Carlos I marcha a trote lento como el Caballero de la Muerte de Durero. No obstante, el árbol y riqueza del paisaje está acorde con composición de Tiziano. El brazo que sostiene el bastón de mando es similar a los retratos de Felipe II y el Cardenal Infante de Rubens del Museo del Prado ${ }^{34}$.

Nosotros vemos la influencia más directa en los grabados alemanes y flamencos que en los italianos. Los caballos de los retratos ecuestres citados andan con las patas derechas e izquierdas en alternancia, mientras que los grabados de Durero, Stradanus y Tempesta, marchan a trote lento, con las manos y patas en diagonal y en perfecta armonía, igual que los caballos de Carlos I que pintó Van Dyck. Es el passage de la alta escuela de equitación que vemos domina en los retratos de Felipe II de Rubens e Isabel de Austria de Velázquez ${ }^{35}$. La equitación en campo abierto fue práctica más frecuente en Inglaterra, y Van Dyck fue un buen conocedor de este ejercicio ecuestre en boga en la nobleza europea. El pintor logra la más perfecta articulación entre caballo y caballero: inmóvil de rodillas a cadera, y móvil de rodillas abajo y de cintura arriba; lo que permite la elasticidad del cuerpo a punto de seguir los movimientos del caballo sin perder la verticalidad y firmeza en la montura. Difiere del retrato heroico de Carlos $V$ de Tiziano, que cabalga en "aire", y más a galope o redoble.

Van Dyck fija un modelo insuperado de retrato heroico, impregnado del poder monárquico con carga simbólica ${ }^{36}$; consciente el monarca inglés de la ayuda de las artes a su poder y magnificencia ${ }^{37}$. La misma armadura es símbolo de virtud heroica ${ }^{38}$. El modelo fue identificado por G. Martín en la Armería Real de la Torre de Londres y talleres reales de Greenwich entre 1610 y 1620, al tratar la réplica de la National Gallery ${ }^{39}$. Advierte la participación de taller en la parte

\footnotetext{
29 Pope-Hennesy, Italian High Renaissance and Baroque Sculpture,Londres y Nueva York, 1970, pp.103-104; Fehl, "The placement of Equestrian Statue of Marcus Aurelius in the Middle Ages" Journal of the Warburg and Courtauld Institute, XXXVII, 1974, pp.362-67; Ackerman, The Architecture of Michelangelo, Londres, 1961, pp.67-68; Liedtke, op.cit. 1989 , p. 96, n.12.

30 Grabado por Crispin van de Passe, Suetonio de Cesarum, XII Vitis, (1470); Hollstein, Dutch and Flemish Etchings, Engravings and Woodcuts ca 1450-1700, 1954-1987, XVI, n 309-320.

31 Emperadores romanos a caballo, Tarragona, 1596. inspirado en el anterior; [Bartsch, Le peintre-graveur, Viena 1874-1876, n $596-607]$.

32 En el Imperio romano el retrato ecuestre fue privilegio sólo del emperador. [Strong, Charles I on horse 1972, p. 49].

33 "ad imitazione di Carlo Quinto espresso da Tiziano" [Bellori, Le vite dépittori, scultori et architetti moderni, Roma, 1672, ed. 1976, p. 260].

34 Véase Díaz Padrón, op.cit., 1995, II, p. 970, nº 1686; p. 974, nº 1687.

35 La modalidad del retrato ecuestre del rey no está en el sentir español, donde el rey es en España un "princeps inter pares", como recuerda Martin de Soria, de quien tomamos estas precisiones de equitación (Archivo Español de Arte, 1954, p.104).

36 Véase Moffit 1983, nº 7, p. 83-93. Se representa en el retrato el ideal del caballero cristiano, encarnando el Miles Christianus. Van Dyck sigue los gustos y modas que impone Carlos I. Documentos de la época muestran al rey como encarnación del caballero cristiano, como el nuevo san Jorge, lo que se muestra en el retrato en la medalla que lleva al cuello. Es rey por derecho divino, y se presenta no sólo como guerrero sino también como caballero.

37 S. Barnes- A.K. Wheelock, en Van Dyck 350; Washington, 1991, p. 249-250.

38 Gordenker, Anthony Van Dyck (1599-1641) and the representation of dress in the Seventeenth Century portraiture, 2001, p. 21.

${ }^{39}$ Martin, op.cit. 1970 , p. 44
} 
baja de la armadura. La espada que lleva el monarca no tiene protector. Es un sutil detalle que no escapó a la fina observación del pintor, que cubre por este motivo la mano del rey con guanteletes de hierro.

La versión de la National Gallery se fecha entre 1635 y $1637^{40}$. Menor tamaño tiene la repetición del castillo de Windsor [Fig. 5] ${ }^{41}$, que algunos estimaron modello preparatorio ${ }^{42}$, y otros reducción ${ }^{43}$. O. Millar tuvo el dibujo del British Museum por un estudio preparatorio [Fig. 6] ${ }^{44}$. Hoy se discute la autoría a Van Dyck proponiéndolo por copia temprana del lienzo de Windsor en los últimos años ${ }^{45}$.

El afortunado retrato ecuestre produjo un abundante número de copias y repeticiones para personajes notables de la época. Muy interesante es para el ámbito español el retrato del Cardenal Infante de igual tamaño que consta en la prestigiosa colección del VII marqués del Carpio (1689) con una elevada estimación ${ }^{46}$. Dependiendo de Van Dyck está el retrato de Sir Thomas Tipping de Bernard Lens (1724) ${ }^{47}$, de la colección Downshire, y del General Philip Honeywood de Gainsborough, en el John \& Marble Ringling Museum de Sarasota ${ }^{48}$.

No obstante son escasas las copias que corresponden con exactitud a los retratos de la National Gallery de Londres y del Museo del Prado: una se atribuye a S. Drummond en venta londinense [Fig. 7 ${ }^{49}$; y otra se conserva en Ickworth [Fig. 8 $]^{50}$. Gregory Martin cita otras atribuida a Charles Jarvis ${ }^{51}$; colección Delme-Radcliffe en Hitchin Priory ${ }^{52}$, y sin precisión en Hellens, Much Marcle (copia del siglo XVIII en escala reducida); y colección Clarendon ${ }^{53}$.

De hecho la mayor parte de las copias responden mejor a la versión más pequeña de Windsor (donde la visera del yelmo está levantada). Destacamos la de Warwik Castle [Fig. 9] ${ }^{54}$; duque de Leeds en Hornby Castle [Fig. 10] ${ }^{55}$; E. Holland [Fig. 11] ${ }^{56}$; Lord Brocket [Fig. 12] ${ }^{57}$ Instituto Colección Nederland de Amsterdam 58 ; venta Sotheby's de Ámsterdam

\footnotetext{
40 Martin, op.cit, 1970, n 1.172; Larsen, op.cit., 1988, II, p. 314, n ${ }^{\circ} 795$; Barnes et al op.cit 2004, pp. 468-470, n $^{\circ}$ IV.51.

${ }^{41}$ L. $96^{\prime} 5$ x $61 \mathrm{~cm}$. Larsen op.cit. 1988, II, p. 313, nº 793; Millar, The Tudor Pictures in the Collection of Her Majesty the Queen, I, 1963, p. 95.

42 Larsen op.cit. 1988, II, p. 314; Barnes et al op.cit. 2004, p. 470, n IV. 52.

43 Martin op.cit. 1970, p. 42.

44 Millar, Tudor, Stuart, and Early Georgian Pictures in the Royal Collection,London, 1963, II, nº 20.

45 Barnes et al op.cit. 2004, p. 471.

46 "Un retrato del Infante Cardenal a caballo en un pais donde hay un arbol grande donde esta colgado un letrero original de Van Dyck de cuatro varas y cuarto de caida y tres varas y tercia de ancho con su marco negro y treinta y tres mil Rs. 33.000" [Burke \& Cherry, Collection of Paintings in Madrid, 1997, t II, pp. 830-877, n 437].

47 Pergamino, 482 x 421 mm. Firmado y fechado 1720. Sotheby’s, 9-VI-1955, nº 26 (Cit. Martin op.ci t1970, p. 44).

Cit. Barnes et al op.cit. 2004, p. 470 (como en la colección Devonshire)

48 Cit. Barnes et al op.cit. 2004, p. 470.

${ }^{49}$ L. 124,5 x 99 cm. Venta Allan Adair (Christie’s, Londres, 8-XII-1950, nº 166) Cit. Martin op.cit 1970, p. 44; que identificamos más tarde muy deteriorada (Sotheby's, Londres, 10-VII-1991, n 102).

${ }^{50}$ L. 73,5 x 58,5 cm [The Esat Wing, Ickworth, Catalogue 1907; Farrer 1907, p. 202]. Vendida por Sotheby's, en la casa, 11/12-VI-1996, no 432.

51 223,5 x 132,1 cm. Venta Charles Jarvis, 12-V-1793, n 47. Cit. Martin op.cit.,1970, p. 44.

52 Antiguamente en Hitchen Priory, (Martin 1970, p. 46).

53 Cit. Barnes et al op.cit. 2004, p. 470.

54 L. 102 x 84 cm. (Christie's, Londres, 11-III-1968, nº 68). Véase Larsen 1988, II, p. 477, nº A 199/2.

55 L. 96 x 86 cm, o 102 x 84 cm (i). Venta Herzog van Leeds, Sotheby’s, Londres 15-XI-1961, nº 5; de nuevo en Sotheby's, Londres 9-IV-1988, n 25.

56 L., 112 x 90 cm. Venta E. Holland Martin, Londres, Christie's, 26-VI-1959, no 73 (como Van Dyck).

${ }^{57}$ L. 96 x 85 cm. Venta Lord Brocket, Londres, Sotheby's, 16-VII-1952, n 93.

5898 x 84,5 cm. (A’dam, VII-1929, nº 45) Mauritshuis, La Haya. Amsterdam, Instituut Collectie Nederland (Inv. N ${ }^{\circ}$ NK 3266) B.M.J. Brenninkmeyer de Roy, Schilderijengalereij Prins Willem V /The Great Prince William V Gallery of
} 


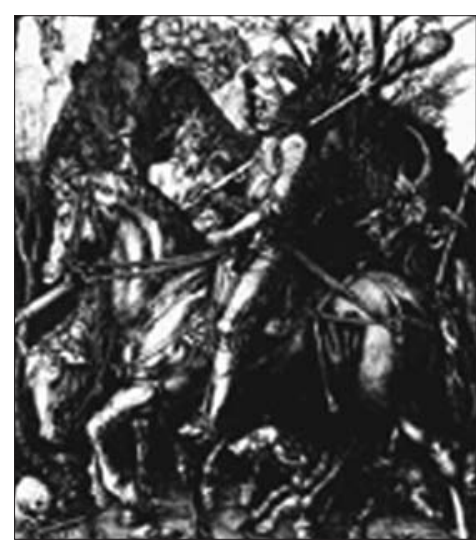

Fig. 4. Alberto Durero. El caballero, la muerte y el diablo. (Grabado. 1513).

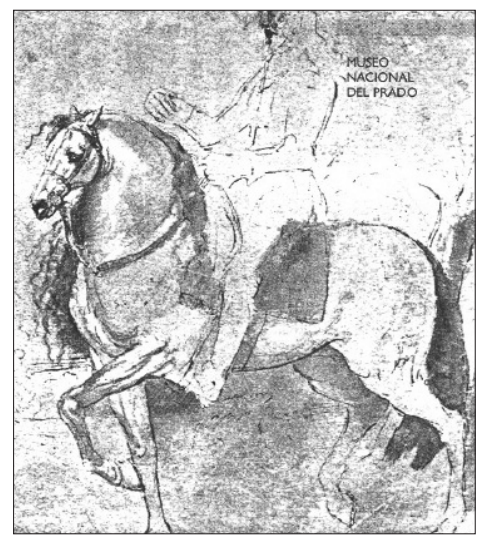

Fig. 6. Según Van Dyck. Carlos I a caballo. Londres, British Museum.

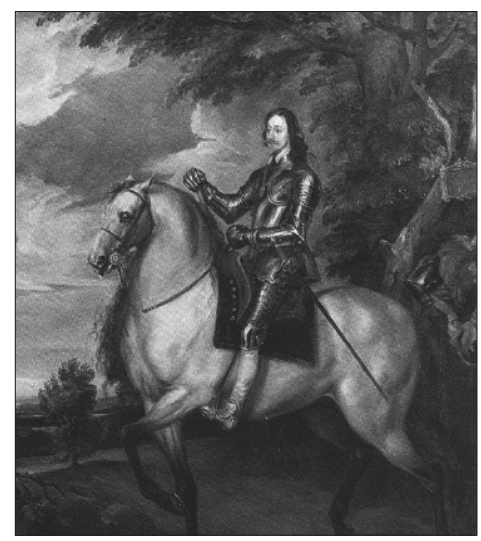

Fig. 8. Según Van Dyck. copia Carlos I. Antigua colección de Ickworth. Paradero desconocido.

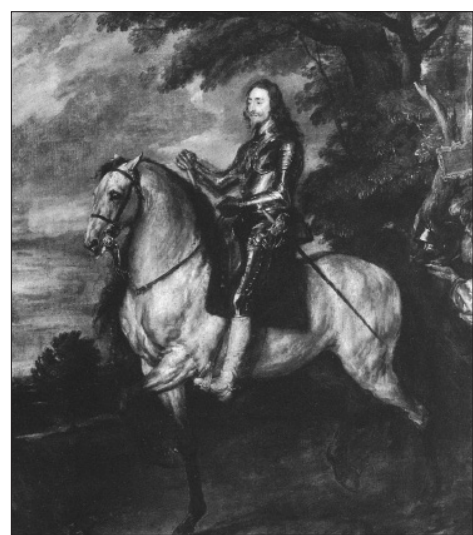

Fig. 5. A. van Dyck. Carlos I a caballo. Windsor Castle, Royal Collection.

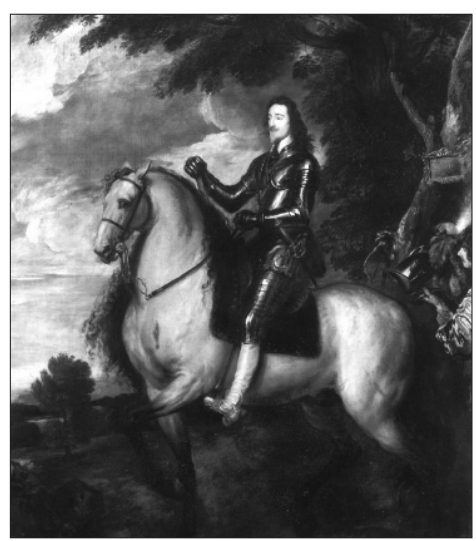

Fig. 7. Atribuido a S. Drummond, según Van Dyck. Carlos I de Inglaterra a caballo. Paradero desconocido.

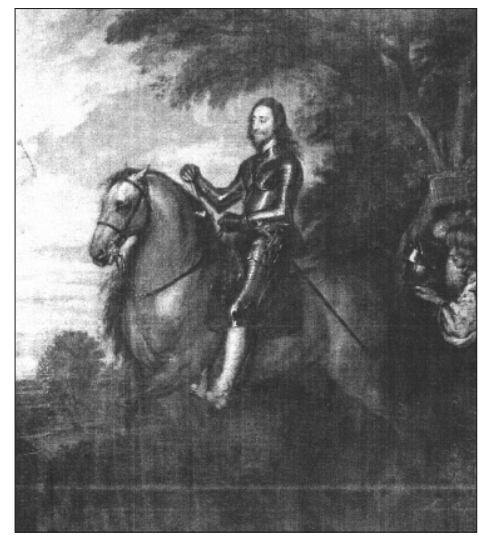

Fig. 9. Según Van Dyck. Copia Carlos I de Inglaterra a caballo. Warwick Castle. Colección del Duque de Warwick. 
[Fig. 13] ${ }^{59}$; antigua colección de George Wombell [Fig. 14] ${ }^{60}$; y venta F.H.T. Jervoise [Fig. 15] ${ }^{61}$. Dos de formato apaisado: una con atribución a Gainsborough en la colección Sepherd [Fig. 16] ${ }^{62}$, otra en Abercairny House, Edimburgo, en la colección Drumond-Moray [Fig. 17] ${ }^{63}$. Otras en Audley End, Ashburnham Place ${ }^{64}$; Welbeck Abbey; Crik Castle; dos en Belvoir Castle; Corsham Court; Stonor Park; Welford Park; Christ Church Museum; y en diversas ventas de Londres, Nueva York y Sidney65.

Algunas versiones omiten el escudero, como la atribuida a Gonzalès Coques en venta de Bruselas [Fig. 18] ${ }^{66}$; y en el mercado artístico londinense sin la vegetación [Fig. 19] ${ }^{67}$. Un ejemplar consta documentado en el palacio de Buenavista en 1759, "un retrato a caballo de van Dyck"68.

A lo expuesto anteriormente sobre el origen del retrato del Museo del Prado, añadimos la más antigua referencia conocida antes en La Granja de San Ildefonso, en 1727, en la colección de Felipe $\mathrm{V}^{69}$, como ratifica el aspa sobre el lienzo y número 54970 . Tras su adquisición por gestión de Alonso de Cárdenas en 1651, Inglaterra, el retrato no consta en las colecciónes de los Austrias.

La revisión de los inventarios llegados a nuestras manos de las colecciones españoles, ha tenido por fruto localizar un retrato en lienzo del rey inglés a caballo de gran tamaño y muy alta tasación en la colección de don Pedro Fernández del Campo Angulo y Velasco, marqués de Mejorada. La tasación en este inventario corrió a cargo de Juan Carreño de Miranda (1680) que cita "un retrato grande del rey de Inglaterra degollado a cavallo, con marco negro, tasado en 300 duca$d o s " 71$. No consta autor alguno, lo que no es extraño en este caso, puesto que no lo hay en todo el listado de la colección. El omitir autores fue frecuente, aunque no dejamos de lamentar esta limitación de datos por parte de Carreño que era pintor de cámara del rey.

Paintings, La Haya, 1982, n 19; Old Master Paintings. An illustrated summary catalogue, Rijksdienst Beeldende Kunst, Zwolle-Den Hague, 1992, p. 92 (como réplica); J. Roberts \& J. Mardsden, The Kings head. Charles I: King and Martyr, Londres, 1999.

${ }^{59}$ L. 99,5 x 88,5 cm. Sotheby's, Ámsterdam, 8-II-1988, nº 160.

${ }^{60}$ L. 160 x $130 \mathrm{~cm}$. Venta Georges Womblell, Londres, Christie’s 9-VII-1948, no 55.

${ }^{61}$ L. 97 x 84 cm. Venta F.H.T. Jervoise, Londres, Sotheby’s, 27-I-1965, nº 144.

62 Dimensiones desconocidas, en la colección Shepherd Bross (ilustrado en The Burlington Magazine, vol. XI, 1907, p. 96).

${ }^{63}$ L. 34,5 x 42 cm. Colección Major James Drummond-Moray, Abercairny House, Edimburgo, 1955.

64 Sotheby's, Londres, 15-VII-1953, n¹57. Cit. Van Barnes et al op.cit. 2004, p. 471, en n IV.52

65 (1) 9-III-1988, no 25, 8-XI-1995, n 36; (2) Christie’s, Nueva York, 6-IV-1989, nº 188; (3) Christie’s Sidney, 15,16-VII-1992, n 756. Cit. Barnes et al op.cit. 2004, p. 471, in $\mathrm{n}^{\circ}$ IV. 52.

66 Dimensiones desconocidas. Venta P. Bezinel, Bruselas, 4-VI-1927, $\mathrm{n}^{\circ} 142$ (como copia de Van Dyck)

67 T., 56 x $36 \mathrm{~cm}$. Christie's, Londres 26-X-1956, nº 36.

68 Aterido et al op.cit 2004, Tomo I pp. 270, 300, n. 107. En el Palacio de Buenavista se registraron ciento y cincuenta y tres "Pinturas que compró SM y otras qe le han presentado diferentes en varias ocasiones" estas obras serían las regaladas a la reina antes y después de 1759, si bien se ha demostrado que algunas permanecían en San Ildefonso,

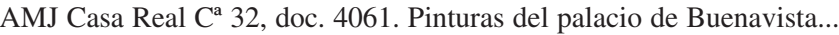

№ 6 Retrato a Caballo de Bandick 31/2Qtas de Ancho 3 Qtas de Caida]

69 "Otra Pintura en lienzo de la escuela de Bandic, que representa el retrato del señor Rei Carlos primero de Inglaterra, Armado, y montado a caballo, y detrás una figura con el morrión en las manos; que tiene quatro varas, y tercia de alto, tres varas, y media menos dos dedos de ancho, y marco dorado liso". Sin tasación, localización dentro de palacio, ni numeración, es sólo una relación y descripción de las obras. Pocas líneas después en el mismo inventario se relacionan las "Pinturas traidas a dho rl. Sitio el año de 1728 en adelante", referencia que aclara que la obra que estudiamos estaba en La Granja con anterioridad a esa fecha. [AGP, Inventario General de las pinturas, muebles y alhajas del Real Sitio de San Ildefonso. Año 1734].

${ }^{70}$ Marca y numeración realizada en inventarios posteriores.

71 1680, Ynventario y Tasazion de los vienes que quedaron por fin y muerte del marqués de Mejorada. AHPM, Prot. 10066, publicado por Barrio Moya, Hidalguía, 1982, pp. 839-855. 


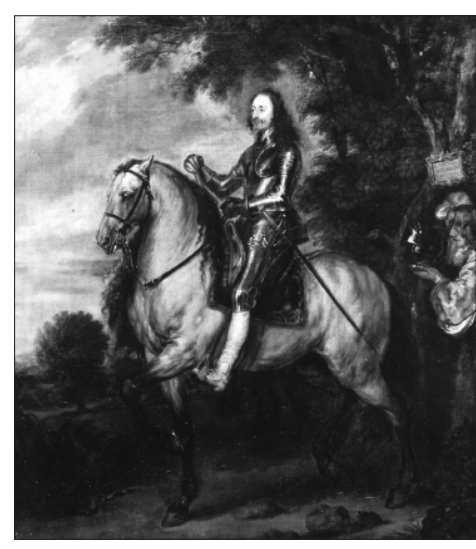

Fig. 10. Según Van Dyck. Copia Retrato de Carlos I de Inglaterra a caballo. Antigua colección del duque de Leeds.

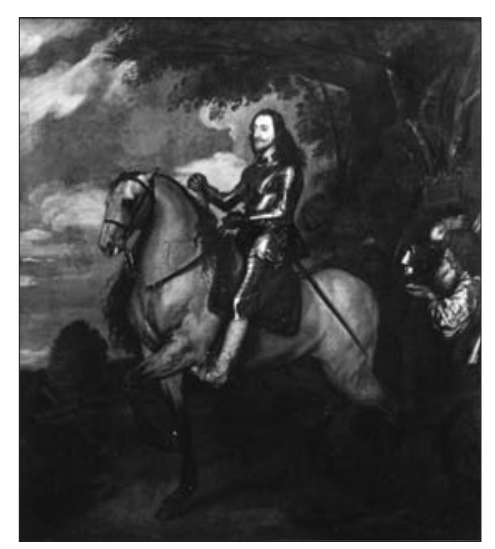

Fig. 12. Según Van Dyck. Copia Carlos I de Inglaterra a caballo. Antigua colección de Lord Bracket.

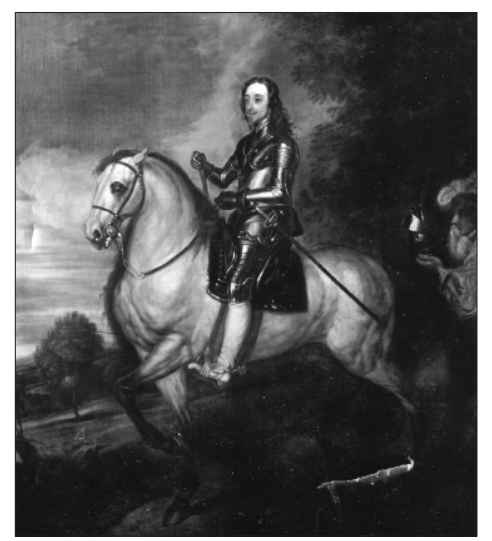

Fig. 14. Según Van Dyck. Copia Carlos I a caballo. Venta Georges Wombwell, Chr, 1948.

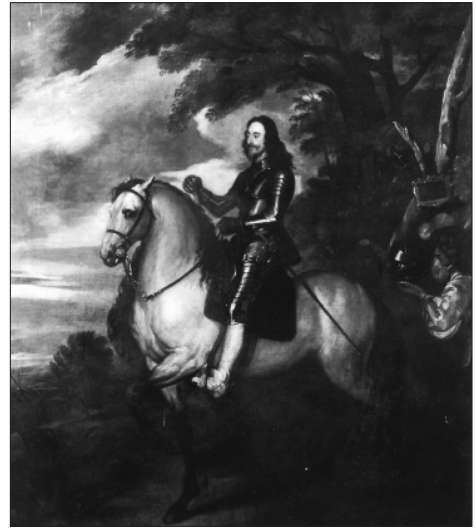

Fig. 11. Van Dyck. Copia Carlos I a caballo. Venta E. Holland.

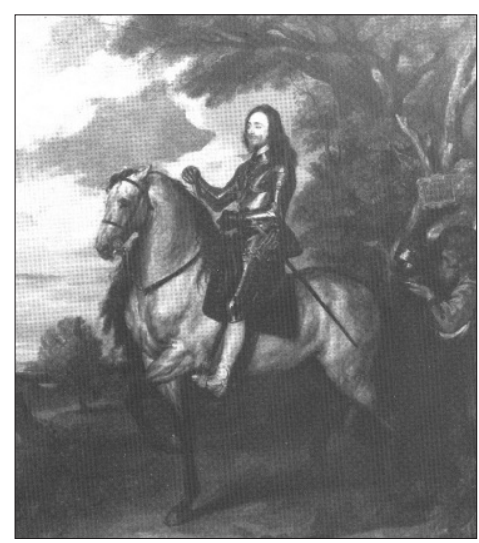

Fig. 13. Según Van Dyck. Copia Carlos I de Inglaterra a caballo. Ámsterdam, (Soth, 1988).

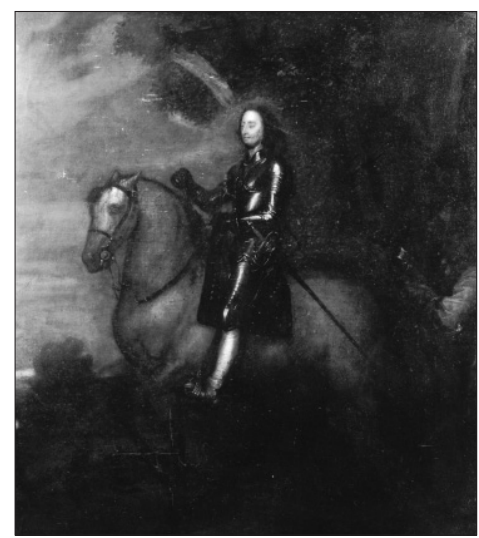

Fig. 15. Según Van Dyck. Retrato de Carlos I de Inglaterra a caballo. (venta Jervoise, 1956). 
El marqués de Mejorada era un rico y poderoso noble del reinado de Felipe IV, consejero del Rey en los consejos de Guerra y de Indias, y Secretario de gobierno en la regencia de doña Mariana de Austria durante la minoría de edad de Carlos II. En 1653 casó con doña Teresa de Salvatierra, fecha de interés por su presencia en la Corte, donde tuvo que relacionarse con los nobles y mecenas más allegados al rey como don Luís de Haro, favorito del monarca. Su suntuoso sepulcro con la estatua orante de su esposa pasó al Museo Arqueológico Nacional al derribarse el convento de los Agustinos Recoletos de Madrid como tantos otros por la desidia de la administración ${ }^{72}$.

Es un eslabón razonable para cubrir su paso a la colección de los Borbones en 1727. Por estas fechas los reyes comienzan a adquirir nuevas pinturas para las residencias de nueva planta fuera de Madrid. No obstante, leemos en una interesante partida del inventario del marqués de Ensenada (1751): "Dos retratos á caballo; el uno de un Rey de Inglaterra, y el otro del Duque de Olivares, de cuatro varas de caida y tres de ancho; el uno de Velázquez y el otro de la escuela flamenca"73. No hay duda que el Conde-Duque a caballo de Velázquez es el que hoy conserva el Museo del Prado, y como pendant con el del rey de Inglaterra de un tamaño afín al retrato de Carlos I del Museo del Prado que estudiamos. Los cuadros de gran formato eran muy del gusto del marqués de la Ensenada, como comentan sus biógrafos.

Presumimos que el retrato del Van Dyck de Carlos de Inglaterra del Museo del Prado del que seguimos los pasos, desde la propuesta de venta a don Alonso de Cárdenas en 1651 y la posesión del marqués de Mejorada hasta 1680, pueda ser el documentado en la colección de Felipe V. No es imposible que lo tuviera por compra o regalo del poderoso ministro ${ }^{74}$. Si bien consta esta pintura en la colección de Felipe V en 1727, con anterioridad al registro del inventario del marqués de Ensenada (1751), parece romperse el previsto seguimiento, pero dos razones nos motivan a pensar que es viable se trate del mismo cuadro. De una parte, no conocemos otro retrato del rey inglés de tales proporciones y contenido que haya llegado a nosotros. Es difícil que un lienzo de tal tamaño y calidad no figure documentado en nuestros días por más celosa desconfianza del coleccionismo privado en España. Tampoco conocemos referencias fuera de España de una pintura con las características del retrato adquirido por Felipe V. De otra parte, es probable que el inventario del marqués de Ensenada registrara no sólo las pinturas que poseía en aquel momento, sino las que había poseído con anterioridad; es decir, que el contenido fuera reflejo de la colección completa del ministro. Existen testimonio de casos afines para cotejar ${ }^{75}$. Más razonable si tenemos en cuenta que el inventario de Ensenada de 1751 fue levantado "con motivo de su destitución como ministro"76, acusado de malversación de fondos del Estado, por lo que se procedió

\footnotetext{
72 V. Poleró, Estatuas tumulares de personajes españoles de los siglos XIII al XVIII, 1903, p. 92

${ }^{73}$ M. Águeda Villar, "Una colección de pinturas en el Madrid del siglo XVII: El Marqués de la Ensenada" en Cinco siglos de arte en Madrid (XV-XX), III Jornadas de arte. Departamento de Historia del Arte "Diego Velázquez". Centro de Estudios Históricos. CSIC, 1991, p. 169.

74 Fue poco después cuando Carlos III compró el lienzo de Velázquez de la misma colección [López Rey, Velázquez, 1979, p. 164]. El retrato del Conde Duque estuvo en posesión de la familia hasta el siglo XVIII, en que lo adquiere el marqués de la Ensenada, hasta la venta de su colección el 26 de enero de 1769, en que Carlos III lo adquirió por 12000 reales de vellón para el nuevo Palacio Real de Madrid [J. Sánchez Cantón, Los pintores de cámara de los reyes de España, 1916, p.82].

75 Es el caso del Acto de devoción de Rodolfo I de Habsburgo de Rubens y Wildens en el Museo del Prado, que se inventaría en el Alcázar de Madrid en 1636 y, años más tarde, en 1655, consta en el inventario de la colección del marqués de Leganés [López Navío 1962, n 105; Véase Díaz Padrón, op.cit. 1995, II, p. 1110, n 1645]. Lo mismo sucede con La Muerte de Séneca de Rubens, inventariado en la colección de Leganés en 1655, cuando debió estar en el Buen Retiro en los años 1630; y con los Bodegones de pescado de Adriaenssens, que figuran en la testamentaría del marqués, a pesar de haber sido previamente regalados al rey [Véase Díaz Padrón, op.cit., 1995, II, p. 1062, n 3048; I, p. 98, nº 1341 y ss].

76 Agueda Villar, op.cit. 1991, p.168.
} 


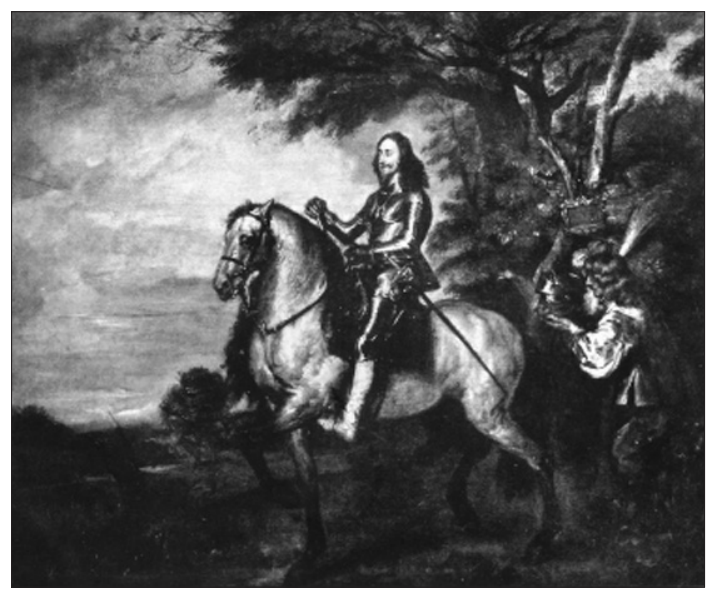

Fig. 16. Según Van Dyck. copia Carlos I de Inglaterra a caballo. Antigua colección Sepherd (1907).

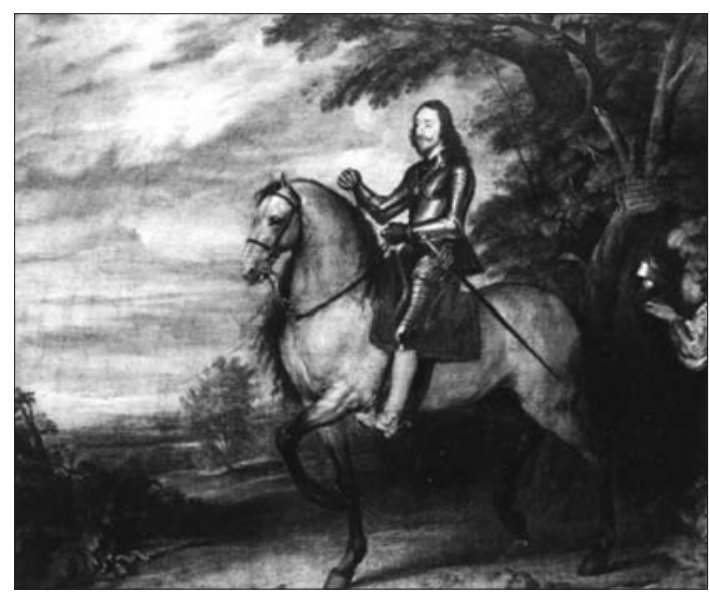

Fig. 17. Según Van Dyck. Copia Carlos I de Inglaterra a caballo. Edimburgo, Abercairny House, Colección Drumond Maray, 1955.

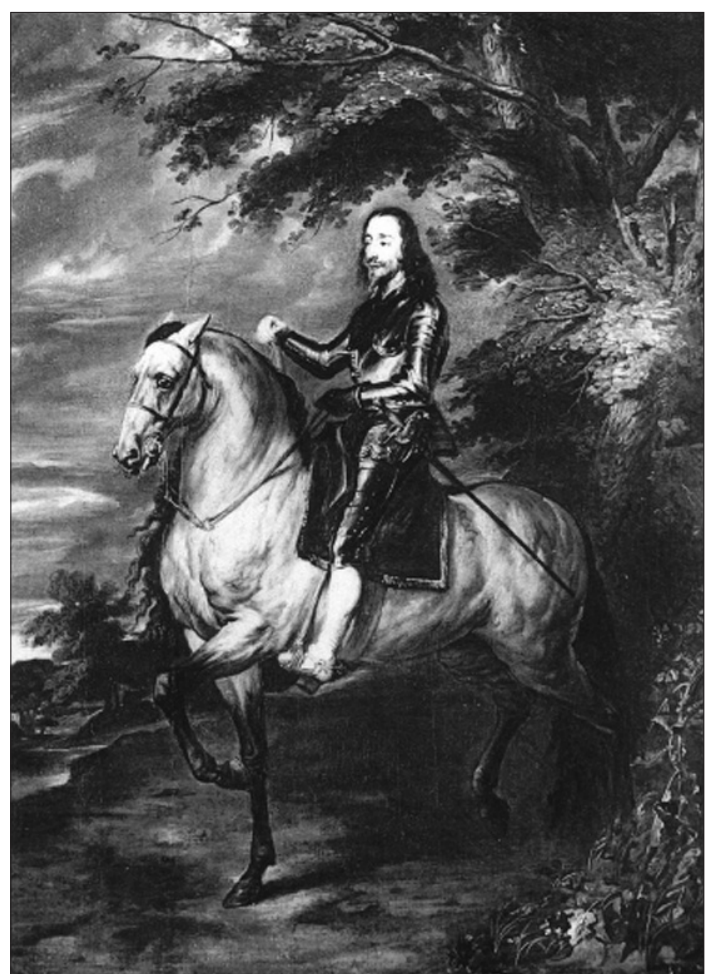

Fig. 18. Según Van Dyck. copia Carlos I de Inglaterra a caballo. Venta de Bruselas, 1927.

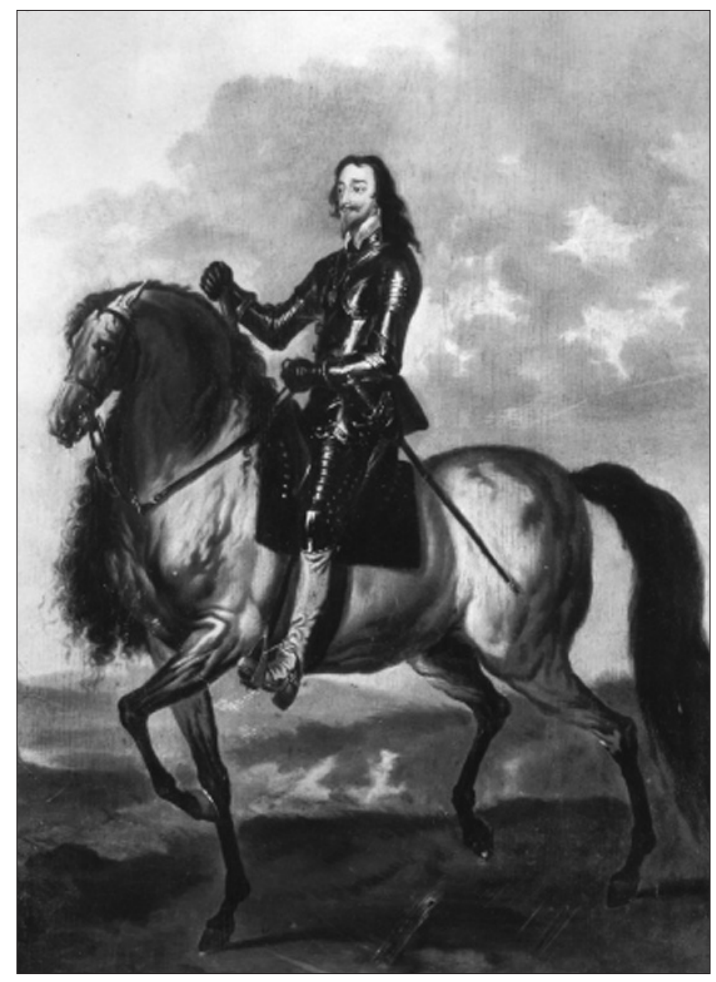

Fig. 19. Según Van Dyck. copia. 
al control de sus bienes. Era conocida su afición al derroche; y Felipe V censuró la ostentosa riqueza de sus trajes ${ }^{77}$. Su colección estaba repartida en su mansión en el barrio alto de Barquillo, próxima al lugar que hoy ocupa el palacio de Buenavista ${ }^{78}$.

Después de 1727 (en que se inventaría en La Granja por vez primera) la documentación prueba su permanencia continuada en el palacio (según atestan los inventarios de 174679, 177480, $1789^{81}$ y 179482 , y 181483). Ingresó en el Museo del Prado a la muerte de Fernando VII (1834). Fue colocado en el Salón segundo consagrado a la escuela flamenca: "320. Carlos I a caballoVan Dyck-16.000"84. Pasaría a los depósitos, donde está hoy.

Sería deseable rescatar del olvido este retrato cuyo gemelo de la National Gallery de Londres centra el muro más amplio del salón del siglo XVII nórdico. La eliminación de los viejos barnices y acumulación de excrecencias desvelaría la calidad y esplendor de este retrato que de forma lapidaria suscribe la memoria del parlamento inglés: "este cuadro es lo mejor que hizo Van Dyck" (85).

77 Su personalidad en Rodríguez Villa 1878; Abad León, El Marqués e la Ensenada, su vida y su obra, Madrid, 1985, 2vols.

78 Mesonero Romanos, El Antiguo Madrid, 1861, p. 246.

79 "549. Otra en lienzo de la escuela de Van dic el retrato del Sr. Rey Carlos primero de Inglaterra armado montado a caballo y detrás una figura con el morrión con las manos de quatro varas y tercia de alto y tres y media menos dos dedos de ancho" [BMPM, Inventarios Reales VII, 1746, (Transcripción), n 12.606; Véase Inventarios 2004, t. II, p. 33, no 549$]$.

80 "549. Quatro varas y tercia de alto tres menos dos dedos de ancho retrato del señor Carlos primero de Inglaterra armado a caballo y detrás una figura con el morrión en las manos se previene tiene a bajo una rotura de un pie mas o menos= escuela de Van Dyck= casa de las Alhajas= 6.000" [BMPM, Inventarios Reales IX, 1774, (Transcripción), $\left.\mathrm{n}^{\circ} 17.410\right]$.

81 “549. tres pies y medio dealto 10 y medio de ancho Carlos I de Inglaterra a caballo Van Dick 6.000" [Fernández-Miranda 1988, II, p. 256, nº 2.336].

82 "549. Otra en lienzo de trece pies y medio de alto: por diez y medio de ancho marco dorado liso representa á Carlos $1^{\circ}$ de Ynglaterra á caballo en seis mil reales. Bandic $=6.000$ ” [BMPM, Inventarios Reales X, 1794, (Transcripción), $\left.\mathrm{n}^{\circ} 18.366\right]$.

83 "549. Trece pies y medio de alto diez y medio de ancho, Carlos I de Inglaterra a caballo= Van Dick" [BMPM, 1814 , p. 23, no 20.286].

${ }^{84}$ BMPM, Inventarios reales. Pinturas del Museo hecho a la muerte de Fernando VII, 1834, XX, p. 63, no 320.

85 Vid. p. 129 , Not. 8 y 9. 